\title{
Oral Health and Masticatory Performance in Adults Submitted to Bariatric Surgery: A Pilot Study
}

\author{
Paula Valeska Tavares ${ }^{1}$, Aline Coelho', Micheline Coelho Ramalho Vasconcelos ${ }^{2}$, \\ Criseuda Maria Benício Barros ${ }^{3}$, Rosa Maria Mariz Melo Sales Marmhoud Coury33, \\ Armiliana Soares Nascimento ${ }^{4}$, Maria da Conceição de Barros Correia5, \\ Luciana de Barros Correia Fontes ${ }^{5 *}$ \\ ${ }^{1}$ Fundação de Ensino Superior de Olinda (Funeso Unesf), Olinda, Brazil \\ ${ }^{2}$ Instituto de Medicina Integral Professor Fernando Figueira (Imip), Recife, Brazil \\ ${ }^{3}$ Universidade Estadual da Paraíba (UEPB), Campina Grande, Brazil \\ ${ }^{4}$ Universidade de Pernambuco (UPE), Camaragibe, Brazil \\ ${ }^{5}$ Universidade Federal de Pernambuco (UFPE), Recife, Brazil \\ Email: ${ }^{\text {lu.bc.f@hotmail.com }}$
}

Received 3 February 2015; accepted 18 March 2015; published 24 March 2015

Copyright (C) 2015 by authors and Scientific Research Publishing Inc.

This work is licensed under the Creative Commons Attribution International License (CC BY). http://creativecommons.org/licenses/by/4.0/

(c) (i) Open Access

\section{Abstract}

Background: Obesity has reached epidemic patterns and constitutes a serious public health problem due to co-morbidities and the impact on life quality of affected individuals. Bariatric surgery appears as one of the most recommended treatments; however much has been known about the effects of this intervention on the functional performance of the organism as a whole. Objective: To characterize the oral health of adults submitted to bariatric surgery, before and after the intervention, with emphasis on the performance of masticatory function. Methods: A prospective observational cohort study conducted in a public reference service to the treatment of obesity in the city of Recife, State of Pernambuco. The data were obtained during the first half of 2011, through interview, intraoral physical examination and evaluation of masticatory function. Statistical treatment adopted was a CI of $95 \%$ and the chi-square test. The collection was conducted in three stages, with initial assessment in the preoperative and follow-up at 60 and 180 days. Results: The sample consisted of 20 volunteers, aged between 23 and 58 years and mean BMI of $43.2 \pm 2.8$. When compared the pre-operative to the control periods, there were significant differences for variables with decreased tendency towards spontaneous gingival bleeding and increased tooth hypersensitivity and tooth mobility $(p<0.05)$. Regarding the masticatory function, we found significant differences for most of the variables investigated, except in the coordination of move-

\footnotetext{
${ }^{*}$ Corresponding author.
} 
ments and breathing during this function. Conclusion: The performance of masticatory function shows differences in pre- and postoperative periods for bariatric surgery.

\author{
Keywords
}

\author{
Obesity, Bariatric Surgery, Oral Health
}

\title{
1. Introduction
}

The World Health Organization (WHO) defines obesity as a chronic, non-transferable disease, characterized by excessive accumulation of adipose tissue around the body that often causes damage to health [1]. Its etiology is multifactorial and complex. Currently obesity is a serious public health problem by its increasing scope, comorbidities and negative impact on life quality of individuals affected [2] [3].

Gastrointestinal surgery for obesity, also called Bariatric Surgery (BS) is an option for people with morbid obesity and who cannot lose weight by traditional methods or suffer from health problems related to obesity, since its moderate condition [4]. With a growing demand for referrals, this type of treatment has raised questions, especially when it comes to changing feeding behavior and its implications [5].

In this context, the feeding behavior and nutrition of the patient undergoing this type of intervention have been associated with masticatory ability. From the surgical intervention, individuals who previously tended to eat faster [6], are encouraged to eat slowly, to optimize digestion. Still, side effects such as gastroesophageal reflux, vomiting and deficiency of vitamins and minerals (calcium, iron, vitamin B12 and D) are observed causing changes in oral health [7].

However few studies address the teeth health conditions and supporting structures of patients submitted to bariatric surgery for this purpose [8].

Considering what was mentioned above, the present study aims at characterizing the oral health of adults submitted to bariatric surgery, before and after the intervention, with emphasis on the improvement in the performance of masticatory function.

\section{Methodology}

This was an observational, prospective cohort study with descriptive analytical data analysis and, considering a confidence interval (CI) of 95\%. The study was conducted at a public reference service for treatment of obesity in Recife, northeastern Brazil, where the sample represented $66.7 \%$ of patients submitted to bariatric surgery.

The inclusion criteria were: patients over 18 years of age, indicated for surgical treatment for morbid obesity, over a period of up to thirty days before the surgery and that proposed to control after 60 and 180 days of the initial assessment. For undergoing the remaining stages of the study, from the first examination, the volunteer had to meet the hospital discharge with normal feeding authorized (except in quantity).

Exclusion criteria included the record or report of mood disorders (dysthymic severe) or mental disorders, patients with neuromotor disorders or other systemic disorders, congenital or genetic with repercussions on the masticatory efficiency.

Data collection occurred between April and June of 2011 (1st and 2nd phases: initial assessment and control at 60 days) and in October and November 2011 (3rd phase: corresponding to the control at 180 days) by the signing of a Consent Letter (head of department) and the Consent Statement by the research participants. Academic students from the courses of Dentistry and Speech Therapy have participated to study, as well as one dentist and one speech pathologist previously calibrated.

Face to face interview with intraoral physical examination and evaluation of masticatory function (with filming, auscultation and palpation) were the sampling tool, applied in the normal referral service under artificial light, with volunteers sit in room granted for this purpose. Apple and bread were used to analyze the masticatory performance being recorded the information on a form specific for the study, with adaptations of the MBGR myofunctional evaluation protocol [9] and the protocol for masticatory clinical evaluation [10]. Criteria for oral health surveys [11] included: the DMFT index (Decay, Missing and Filled Teeth), spontaneous gingival bleeding, halitosis, tooth mobility, malocclusion and dentin hypersensitivity. 
The statistical analysis was performed using SPSS 18. Continuous variables were presented as mean \pm standard deviation and chi-square test and the categorical variables in the form of relative frequency.

No conflict of interest, the study was approved by the Research Ethics Committee (REC) of the Federal University of Pernambuco, UFPE, under the protocol number 259/09 and started after signing the Letter of Consent by the responsible regarding the investigated service and signing the informed consent by the study volunteers.

\section{Results}

This sample consisted of 20 volunteers, aged between 23 and 58 years, with average age of 39 years and standard deviation 3.6. Volunteers had an average family income under U\$600.

The socio-demographic characteristics of the patients involving in this study were summarized in Table 1. The mean weight recorded at the initial examination was $98 \mathrm{~kg} \pm 27.1 \mathrm{~kg}$, with mean height of $153 \mathrm{~cm} \pm 12.3$ $\mathrm{cm}$ and mean of Body Mass Index (BMI) $43.2 \pm 2.8 \mathrm{Kg} / \mathrm{m}^{2}$. Co-morbidities: hypertension (60\%), diabetes (40\%) or dyslipidemia (25\%), in decreasing order of frequency. These were followed in the pre-operative and postoperative phase (control 60 days and 180 days), underlining a mean weight loss of 5.3\% (at 180 days). There were improvements in co-mordidades associated with obesity, in the postoperative phase (reported by patients), but no specific records.

These adults have a mean number of permanent teeth remaining of 23.2. Overlooking the mean DMFT, we obtained: 9.1, 9.1 and 9.9 and the respective standard deviations for the initial examination and the controls with 60 and 180 days: 1.3, 1.3 and 1.4, with differences only for the missing or extracted components. Concerning to the malocclusions, four patients had posterior crossbite and two patients with deep overbite, all female.

Table 2 shows the distribution of those evaluated according to the oral features displayed by most of the sample, considering the search steps. Through the chi-square test, there was significant difference between the initial examination and that one performed on 180 days $(p<0.05)$ for the variables spontaneous gingival bleeding, tooth hypersensitivity and tooth mobility.

Table 3 shows the masticatory pattern of the volunteers in this research for the preoperative evaluation.

Table 1. Socio-demographic characteristics in this sample of patients.

\begin{tabular}{lc}
\hline \multicolumn{1}{c}{ Variables } & $\mathbf{N}(\%)$ \\
\hline Volunteers & $20(100)$ \\
Female & $17(85)$ \\
Male & $3(15)$ \\
Level of education & \\
Completed secondary education & $10(50)$ \\
Incomplete primary education & $8(40)$ \\
Complete higher education at university & $2(10)$ \\
Degree of obesity & \\
III [Body Mass Index $\left.\geq 40 \mathrm{Kg} / \mathrm{m}^{2}\right]$ & $13(65)$ \\
II [Body Mass Index 35 to $\left.39.9 \mathrm{Kg} / \mathrm{m}^{2}\right]$ & $7(35)$ \\
\hline
\end{tabular}

Table 2. Distribution of the patients according to the oral characteristics and stage of the study.

\begin{tabular}{cccc}
\hline \multirow{2}{*}{ Oral characteristics } & \multicolumn{3}{c}{ Stage of the study (evaluation) } \\
\cline { 2 - 4 } & Preoperative N (\%) & $\mathbf{6 0}$ days N (\%) & $\mathbf{1 8 0}$ days N (\%) \\
\hline Gingival bleeding & $13(65 \%)$ & $12(60 \%)$ & $7(35 \%)^{*}$ \\
Halitosis & $14(70 \%)$ & $14(70 \%)$ & $13(65 \%)$ \\
Tooth mobility & $6(30 \%)$ & $7(35 \%)$ & $11(55 \%)^{*}$ \\
Malocclusion & $6(30 \%)$ & $6(30 \%)$ & $6(30 \%)$ \\
Dentin hypersensitivity & $5(25 \%)$ & $5(25 \%)$ & $9(45 \%)^{*}$ \\
\hline
\end{tabular}

CI of $95 \%$ and the chi-square test ${ }^{*} p<0.05$. 
Table 3. Chewing pattern of the volunteers during preoperative evaluation.

\begin{tabular}{|c|c|c|c|}
\hline \multirow{2}{*}{ Variables } & \multirow{2}{*}{$\begin{array}{c}\text { Preoperative } \\
\text { N (\%) }\end{array}$} & \multicolumn{2}{|c|}{ After bariatric surgery } \\
\hline & & 60 days & 180 days \\
\hline \multicolumn{4}{|c|}{ Preferred food consistency } \\
\hline Solid & $12(60 \%)$ & $4(20 \%)$ & $6(30 \%)^{*}$ \\
\hline Paste & $4(20 \%)$ & $6(30 \%)$ & $6(30 \%)^{*}$ \\
\hline Liquid & $4(20 \%)$ & $10(50 \%)$ & $8(40 \%)^{*}$ \\
\hline \multicolumn{4}{|c|}{ Masticatory preference side } \\
\hline Both & $7(35 \%)$ & $12(60 \%)$ & $10(50 \%)^{*}$ \\
\hline Right & $4(20 \%)$ & $3(15 \%)$ & $1(5 \%)^{*}$ \\
\hline Left & $9(45 \%)$ & $5(25 \%)$ & $9(45 \%)$ \\
\hline \multicolumn{4}{|c|}{ Presence of chocking } \\
\hline Yes & 7 (35\%) & $4(20 \%)$ & $4(20 \%)^{*}$ \\
\hline No & $13(65 \%)$ & $16(80 \%)$ & $16(80 \%)$ \\
\hline \multicolumn{4}{|c|}{ Chewing with mouth open } \\
\hline Yes & $7(35 \%)$ & $5(25 \%)$ & $5(25 \%)$ \\
\hline No & $13(65 \%)$ & $15(75 \%)$ & $15(75 \%)$ \\
\hline \multicolumn{4}{|l|}{ Chewing speed } \\
\hline Slow & $4(20 \%)$ & $10(50 \%)$ & $8(40 \%)^{*}$ \\
\hline Regular/Normal & $6(30 \%)$ & $9(45 \%)$ & $8(40 \%)$ \\
\hline Fast & $10(50 \%)$ & $1(5 \%)$ & $4(20 \%)^{*}$ \\
\hline \multicolumn{4}{|l|}{ Pain when chewing } \\
\hline Yes & $4(20 \%)$ & $4(20 \%)$ & $6(30 \%)$ \\
\hline No & $16(80 \%)$ & $16(80 \%)$ & $14(70 \%)$ \\
\hline \multicolumn{4}{|c|}{ Difficult to open or close the mouth } \\
\hline Yes & $5(25 \%)$ & $5(25 \%)$ & $5(25 \%)$ \\
\hline No & $15(75 \%)$ & $15(75 \%)$ & $15(75 \%)$ \\
\hline \multicolumn{4}{|c|}{ Coordination of movements } \\
\hline Yes & $10(50 \%)$ & $10(50 \%)$ & $8(40 \%)$ \\
\hline No & $10(50 \%)$ & $10(50 \%)$ & $12(60 \%)$ \\
\hline \multicolumn{4}{|c|}{ Breathing during mastication } \\
\hline Yes & $8(40 \%)$ & $4(20 \%)$ & $5(25 \%)^{*}$ \\
\hline No & $12(60 \%)$ & $16(80 \%)$ & $15(75 \%)$ \\
\hline
\end{tabular}

CI of $95 \%$ and the chi-square test ${ }^{*} p<0.05$.

According to the chi-square test, there was significant difference $(p<0.05)$ between baseline and postoperative period for most of variables, except: chewing with mouth open, pain when chewing, difficult to open or close the mouth and coordination of movements.

The evaluated individuals were referred to a public health center for treatment in dentistry and speech therapy, according to the observed needs.

\section{Discussion}

The present study shows the side effects of bariatric surgery in the oral health conditions and masticatory performance in patients with morbid obesity. Women (85\%) represented the group that most undergoes this type of treatment, fact based on the demand for improvements in life quality and aesthetic reasons, imposed by society [12].

The current scenario of obesity as a public health problem worldwide has encouraged surgical alternatives for individuals with difficulties in adjusting the most common treatment programs. In this context, despite the high rates of bariatric surgery, studies on the implications of this intervention are scarce, particularly in the functional performance of the organism. It is known that the parameters for a better life quality of obese individuals undergoing this type of intervention are directly related to the prevention and treatment of possible side effects 
[13].

According to the study of Heling et al. [14], the oral implications of bariatric surgery are not adequately reported in the scientific literature. Among the research points highlighted are included the tooth decay, periodontal disease, salivary flow, palate ulcers, parotid hypertrophy, dental erosion and tooth hypersensitivity. In the present work we used the DMFT index in the evaluation of dental caries, spontaneous gingival bleeding, and presence of halitosis and tooth mobility as variables related to periodontal problems, and survey on the presence of malocclusion and dentin hypersensitivity.

Thus, there was increased DMFT after surgery (9.9 mean value for control of 180 days), a characteristic also found in surveys of Hague and Baechle [15] Marsicano et al. [16] Alm et al. [17]. Bailleul-Forestier et al. [18], the latter emphasizing a significant difference in the mean values between non-obese (4.3) and obese (6.9) people. This process is explained by the increasing the rate of bacterial plaque, resulting from the higher food frequency and low salivary flow.

Regarding the evaluation of the variable spontaneous gingival bleeding, there was reduction in this index, considering the fact that after the CB there is reduction in the levels of C-reactive protein by decreased BMI and consequent reduction of adipose tissue. The adipose tissue, acting as a reservoir of inflammatory mediators, leads to increased probability of the host inflammatory response in periodontal disease. Also, one can explain these data by the reduction of medication use for co-morbidities [19]. According to Nascimento et al. [20] the relationship between periodontal health and obesity may exist, but the mechanism that would explain this association remains unclear. The risk factors that aggravate these diseases should be better clarified to elucidate the direction of this association. Life-course epidemiology could be a useful instrument to investigate a casual association between early exposures and later outcomes, being appropriate for understanding the establishment of chronic conditions.

The increased tooth mobility can be explained by the vitamin D deficiency observed in the postoperative CB, which usually leads to development of bone metabolic diseases such as osteoporosis. Osteoporosis influences the bone loss, leading to tooth loss [21].

With reference to the variables dentin hypersensitivity, malocclusion and halitosis among obese individuals, little is established in comparative terms by the lack of studies more targeted to the subject and with such methodology. However, it is known that the gastroesophageal reflux results in dental erosion and consequently hypersensitivity could be established [22].

In this present study, the mean of DMFT index increased after the bariatric surgery. According to the study of Östberg et al. [23] the number of carious lesions and masticatory function showed no associations with obesity, but there were associations between oral health and obesity, particularly with regard to behavior, such as irregular dental visits and with BMI. Therefore the choice of obesity measure in oral health studies should be carefully considered.

Sánchez-Ayala, Campanha and Garcia [24] development a cross-sectional study to investigate the relationship between body fat and masticatory function with one hundred dentate and partially edentulous participants (mean age $39.7 \pm 16.6$ years). Masticatory function was evaluated by quantifying occlusal pairs and determining masticatory efficiency and swallowing threshold with the sieving method. During the swallowing threshold test, chewing rate was registered. Masticatory ability was also evaluated with a 5-point Likert scale questionnaire. Their results showed that masticatory ability and swalowint threshold were related to BMI. Age and lower masticatory efficiency were predictive of increased body fat. Gender and chewing rate were no related to BMI.

Although the association between bariatric surgery and oral health conditions presents a strong foundation in literature, besides the data obtained in this study, no protocol related to bariatric surgery includes, effectively, the dental surgeon in the multidisciplinary team or even indicates dental evaluations prior to the procedure. The results of this present study do not necessarily generalize. A pilot study is a requisite initial step. It's necessary a larger, ensuing hypothesis testing study. Even considering the limitations of this present study, the results point to the need to adequate oral health care for the obese patient in the planning, especially when there being need for a surgical intervention.

\section{Conclusion}

Despite the beneficial effects of bariatric surgery on general health status, negative effects reflect on the oral health status and performance of masticatory function. Therefore, it becomes necessary to integrate the dental 
surgeon in the multidisciplinary team, monitoring of these patients pre- and postoperatively.

\section{References}

[1] Organização Mundial de Saúde (2006) Obesity and Overweight. Report of the WHO Consulation on Obesity. WHO, Geneva.

[2] Khawali, C., Ferraz, M.B., Zanella, M.T. and Ferreira, S.R.G. (2012) Evaluation of Quality of Life in Severely Obese Patients after Bariatric Surgery Carried out in the Public Healthcare System. Arquivos Brasileiros de Endocrinologia \& Metabologia, 56, 33-38.

[3] Sturm, R. and An, R. (2014) Obesity and Economic Environments. CA: A Cancer Journal for Clinicians, 64, 337-350. http://dx.doi.org/10.3322/caac.21237

[4] Pataky, Z., Carrard, I. and Golay, A. (2011) Psychological Factors and Weight Loss in Bariatric Surgery. Current Opinion in Gastroenterology, 27, 167-173. http://dx.doi.org/10.1097/MOG.0b013e3283422482

[5] Scholtz, S., Miras, A.D., Chhina, N., Prechtl, C.G., Sleeth, M.L., Daud, N.M., et al. (2014) Obese Patients after Gastric Bypass Surgery Have Lower Brain-Hedonic Responses to Food than after Gastric Banding. Gut, 63, 891-902. http://dx.doi.org/10.1136/gutjnl-2013-305008

[6] Sato, N. and Yoshiike, N. (2011) Dietary Patterns Affect Occlusal Force but Not Masticatory Behavior in Children. Journal of Nutritional Science and Vitaminology, 57, 258-264. http://dx.doi.org/10.3177/jnsv.57.258

[7] Shikora, S.A., Kim, J.J. and Tarnoff, M.E. (2007) Nutrition and Gastrointestinal Complications of Bariatric Surgery. Nutrition in Clinical Practice, 22, 29-40. http://dx.doi.org/10.1177/011542650702200129

[8] Godlewski, A.E., Veyrune, J.L., Nicolas, E., Ciangura, C.A., Chaussain, C.C., Czernichow, S., et al. (2011) Effect of Dental Status on Changes in Mastication in Patients with Obesity Following Bariatric Surgery. PLoS One, 6, e22324. http://dx.doi.org/10.1371/journal.pone.0022324

[9] Genaro, K.F., Berretin-Felix, G., Rehder M.I.B.C. and Marchesan, I.Q. (2009) Avaliação Miofuncional OrofacialProtocolo MBGR. Revista CEFAC, 11, 237-255. http://dx.doi.org/10.1590/S1516-18462009000200009

[10] Whitaker, M.A., Trindade Júnior, A.S. and Genaro, K.S. (2009) Proposta de protocolo de avaliação clínica da função mastigatória. Revista CEFAC, 11, 311-323. http://dx.doi.org/10.1590/S1516-18462009005000030

[11] World Health Organization (1997) Oral Health Surveys: Basic Methods. WHO, Geneva.

[12] Baceviciene, M., Reklaitiene, R. and Tamosiunas, A. (2009) Effect of Excess Body Weight on Quality of Life and Satisfaction with Body Image among Middle-Aged Lithuanian Inhabitants of Kaunas City. Medicina, 45, 565-573.

[13] Marcelino, L.F. and Patrício, Z.M. (2011) A complexidade da obesidade e o processo de viver após a cirurgia bariátrica: Uma questão de saúde coletiva. Ciência \& Saúde Coletiva, 16, 4767-4776.

[14] Heling, I., Sgan-Cohen, H.D., Itzhaki, M., Beglaibter, N., Avrustis, O. and Gimmon, Z. (2006) Dental Complications Following Gastric Restrictive Bariatric Surgery. Obesity Surgery, 16, 1131-1134. http://dx.doi.org/10.1381/096089206778392211

[15] Hague, A.L. and Baechle, M. (2008) Advanced Caries in a Patient with a History of Bariatric Surgery. Journal of Dental Hygiene, 82, 22.

[16] Marsicano, J.A., Sales-Peres, A., Ceneviva, R. and Sales-Peres, S.H. (2012) Evaluation of Oral Health Status and Salivary Flow Rate in Obese Patients after Bariatric Surgery. European Journal of Dentistry, 6, 191-197.

[17] Alm, A., Isaksson, J., Fåhraeus, C., Koch, G., Andersson-Gäre, B., Nilsson, M., et al. (2011) BMI Status in Swedish Children and Young Adults in Relation to Caries Prevalence. Swedish Dental Journal, 35, 1-8.

[18] Bailleul-Forestier, I., Lopes, K., Souames, M., Azoguy-Levys, S., Frelut, M.L. and Boy-Lefevre, M.L. (2007) Caries Experience in a Severely Obese Adolescent Population. International Journal of Paediatric Dentistry, 17, 358-363. http://dx.doi.org/10.1111/j.1365-263X.2007.00848.x

[19] Agrawal, V., Krause, K.R., Chengelis, D.L., Zalesin, K.C., Rocher, L.L. and McCullough, P.A. (2009) Relation between Degree of Weight Loss after Bariatric Surgery and Reduction in Albuminuria and C-Reactive Protein. Surgery for Obesity and Related Diseases, 5, 20-26. http://dx.doi.org/10.1016/j.soard.2008.07.011

[20] Nascimento, G.G., Leite, F.R., Correa, M.B., Horta, B.L., Peres, M.A. and Demarco, F.F. (2014) Relationship between Periodontal Disease and Obesity: The Role of Life-Course Events. Brazilian Dental Journal, 25, 87-89. http://dx.doi.org/10.1590/0103-6440201300019

[21] Tucker, O.N., Szomstein, S. and Rosenthal, R.J. (2007) Nutritional Consequences of Weight-Loss Surgery. Medical Clinics of North America, 91, 499-514. http://dx.doi.org/10.1016/j.mcna.2007.01.006

[22] Moravec, L.J. and Boyd, L.D. (2011) Bariatric Surgery and Implication for Oral Health: A Case Report. Journal of Dental Hygiene, 85, 166-176. 
[23] Östberg, A.L., Bengtsson, C., Lissner, L. and Hakeberg, M. (2012) Oral Health and Obesity Indicators. BMC Oral Health, 12, 50. http://dx.doi.org/10.1186/1472-6831-12-50

[24] Sánchez-Ayala, A., Campanha, N.H. and Garcia, R.C. (2013) Relationship between Body Fat and Masticatory Function. Journal of Prosthodontics, 22, 120-125. http://dx.doi.org/10.1111/j.1532-849X.2012.00937.x 